\title{
The efficacy of alternative (biorational) insecticides in suppressing damage caused by insect pests affecting callaloo, Amaranth xanthosoma and pak choy, Brassica rapa, production in Jamaica
}

\begin{abstract}
Changes in climate are likely to result in more frequent and intense pest outbreaks. The pervasive use of broad spectrum synthetic insecticides within agricultural production systems in Jamaica is likely to lead to the increased use of synthetic pesticides, which are known to have adverse environmental effects and increase the risk of unacceptable levels of residue entering the food chain.

This study aimed to assess the efficacy of selected biopesticides against insect pests affecting callaloo and pak choy production in the parishes of Clarendon, St Elizabeth and Kingston. Monitoring began a week after plots were established to assess pest damage and treatments done when damage reached a pre-determined economic threshold. Yield was assessed at the end of the crop cycle.

The percentage damaged leaves varied significantly $(\mathrm{P}=0.012)$ by type and location of crop ranging from $35.49 \pm 2.53 \%$ in Kingston to $69.89 \pm 2.71 \%$ in St. Catherine. However, there was no significant difference in the harvested yield (315.2 $\pm 11.8-475.7 \pm 33.0$ grams/plant). There was also no significant difference in the marketable yield from plots treated with biorationals $(211.2 \pm 31.3 \mathrm{~g}-288.1 \pm 16.1$ grams/plant) when compared to plots treated with synthetic pesticides $(188.5 \pm 13.3 \mathrm{~g}-216.6 \pm 26.5 \mathrm{grams} /$ plant $)$
\end{abstract}

Keywords: biopesticides, synthetic insecticides, callaloo Amaranth xanthosoma, pak choy
Volume 5 Issue 2 - 202I

\author{
Nadia D Mc Donald, Machel A Emanuel, \\ Dwight E Robinson \\ Department of Life Sciences, Faculty of Science and Technology, \\ The University of the West Indies, Jamaica
}

Correspondence: Machel A Emanuel, Department of Life Sciences, Faculty of Science and Technology, The University of the West Indies, Mona Campus, Kingston 7, Jamaica,

Email machel.emanuel02@uwimona.edu.jm

Received: February 18, 202I | Published: March 04, 2021

\section{Introduction}

Agriculture today faces the challenge of increasing crop yields in the face of climate change while addressing the level of environmental degradation caused by neo-conventional farming practices. The rise of the Green revolution in the mid 20th century introduced a wave of intensive agricultural practices such as monocropping and the widespread use of broad- spectrum conventional insecticides. These insecticides, such as organochlorines, organophosphates and carbamates, were later discovered to cause soil, water and even air pollution. ${ }^{1}$ Research has pointed to the severe adverse effects on environment, problems of resistance reaching crises proportions and public demand for alternatives has motivated governments and agricultural agencies to adopt more sustainable practices which saw the development of biorational pesticides.

The management of pest within an agricultural eco-system is a critical component to ensure the farmers get returns from their investment. Therefore, pest management is a crucial component in the cropping cycle that will ensure a successful harvest. The majority of farmers in developing countries have demonstrated their pervasive use of broad-spectrum conventional insecticides. However, the evidence has demonstrated the negative impacts on flora and fauna, natural resources and hazardous implications towards human health. Due to the intensive pesticide usage over the past fifty years, pesticides and their metabolites can be detected everywhere from fresh water, ground water, soil and even the oceans. ${ }^{2}$ In many instances the concentrations of the active ingredients in these pesticides are found to exceed the established norms and threshold values.

Data from the Pesticide Control Authority (PCA) of Jamaica has indicated that approximately 2.9 million kilograms of pesticides are imported into the island each year and more than $50 \%$ of this is used in the agricultural sector (PCA, Pers. Comm.). Some of these pesticides are classified to be of moderate to high toxicity and there are concerns that residues of these pesticides may end up in the food chain and beyond. In an attempt to monitor this, the PCA regularly conducts a random sample of fruits and vegetables to do a qualitative and quantitative assessment of pesticide residues. While the PCA has indicated that the majority of the fruits and vegetables sampled had no detectable residues, there were five fruits and/or vegetables, Cabbage, Callaloo, Pak Choy, Pepper and Thyme, that frequently had detectable levels of synthetic pesticide residues (PCA, Pers. Comm.). This poses a potential risk to the health of the Jamaican population and environment, therefore, the authorities involved need to understand the direr need for a different approach to public health and safety by moving away from broad-spectrum conventional insecticides to finding less hazardous and persistent products for use in the suppression of pest populations within the agriculture sector. 
The current study was designed to provide data that will assist in the promotion of alternatives (biorationals) to the widespread application of broad-spectrum conventional insecticides for callaloo Amaranth xanthosoma and pak choy Brassica rapa, production in Jamaica.

\section{Materials and methods}

\section{Study sites}

The research plots were established at Mona in Kingston, Douglas Castle in St. Ann and Elim in St. Elizabeth.

The University of the West Indies, Department of Life Sciences Botany Garden is located in the capital Kingston. The Botany Garden is a research facility where the Department of Life Sciences conducts its experiments to facilitate teaching and research for its staff and students. The property is approximately 2.5 hectares where intensive agriculture is practiced consistently.

The Sydney Pagon Science, Technology, Engineering and Mathematics (STEM) Academy is located in the Elim district, Brae's River on the agricultural plains of St Elizabeth. The High School was formerly called the Elim Agricultural School, which served as a secondary level training facility for Jamaica's agriculture sector by graduating students with competent skills in various aspects of agronomy. Today the school still maintains its agricultural curriculum and contributes to the local wholesales and supermarkets with their agricultural produce.

Mr. Stephen Douglas is a conventional farmer from the farming community of Douglas Castle located in the parish of St. Ann. Mr Douglas belongs to the Douglas Castle Benevolent Society that comprises of a community of farmers with similar objectives. Agriculture has been the economic mainstay of the community for decades and the Douglas Castle district in particular has been called the "bread basket" for the parish, well known for its production and supply of food produce, especially vegetables across the island.

According to the PCA, the agricultural plains of St. Elizabeth and the farming community of Douglas Castle were two agricultural districts where there was detection of high levels of pesticide residues on vegetable production according to the Codex Alimentarius pesticide Maximum Residue Limits (MRLs). Therefore, working with the Sydney Pagan Academy, Mr. Douglas and the Benevolent Society should facilitate demonstrations of the relative efficacy of broad-spectrum conventional insecticides vs. biorationals when used within the vegetable cropping system to deter and reduce the impact of pest damage on crops.

\section{Establishment of plots}

The research and demonstration plots were established on the grounds of the Sydney Pagon Academy in Elim, St. Elizabeth, $\mathrm{Mr}$ Stephen Douglas' farm in Douglas Castle, St. Ann and in the Botany Garden at the University of the West Indies, Mona in St. Andrew. A Randomized block design, consisting of sub-plots each containing 25 plants, was used at the Sydney Pagon Academy and in the Botany Garden, with three replicates. A split plot, consisting of plots of approximately 100 plants, was used in Douglas Castle with three replicates.

The plots were established with callaloo, Amaranth xanthosoma and Pak Choy, Brassica rapa seedling all produced in the Department of Life Sciences greenhouse. Approximately one week after seedling emergence, three hundred seedlings of the vegetable crops were transported to each site and transplanted in accordance with the experimental design. The agronomic practices during the life of the crop were consistent with farmer practices in the farming communities where the plots were established, with the exception of pest control practices.

\section{Pest damage assessment and pesticide application}

Once it was determined the pest damaged observed attained a pre- determined economic threshold, plots were randomly selected in each block for treatment. Plots were treated either with biopesticide or the synthetic pesticide usually applied by the farmers on callaloo Amaranth xanthosoma and pakchoy Brassica rapa. One plot in each block was left untreated as a control. Six plants in each plot were randomly selected for assessment and data collection. The number of leaves on each of the selected sample plants was determined and the number of damaged leaves recorded. Three damaged leaves were chosen at random from each sample plant and the length, width and number of holes due to pest injury noted. The size of three of the damaged areas of three randomly selected holes that were due to pest injury was estimated by comparing with fixed areas on a damage assessment card.

After the weekly collection of data the various treatments of biopesticides and synthetic pesticides were reapplied to each plot of crops being monitored once determined by consulting the farmer, that the economic threshold was attained. In Douglas Castle and Sydney Pagon, the synthetic pesticide Karate Zeon (ai. Lambda-cyhalothrin) was applied to the Callaloo and Pak Choy. The biorational Neem-X (ai. Azadirachtin) was applied to the Callaloo and Pak Choy in the Douglas Castle, Sydney Pagon and the Botany Garden plots. The pesticides were applied using the same brand of hydrolytic backpack sprayer, fitted with the same nozzle and operated by the same applicator at all three study sites. The equipment was calibrated prior to each application to ensure that the application rates for each crop and the different stages of the crops were consistent with the manufactures recommendation.

\section{Crop yield}

On reaching maturity the crops were harvested and the total weight of the harvested crop determined at each site. The products were then selected and prepared for market and the marketable weight recorded.

\section{Statistical analysis}

The data was collated and summarized in Microsoft Excel (Version 2013) and SPSS Version 19. Data was statistically analysed by conducting an ANOVA on the data using SPSS. In all cases, significant differences were defined as those with $\mathrm{p}<0 \cdot 05$.

\section{Results}

\section{Damaged leaves}

The percentage damage leaves for callaloo cultivated at the three research plots (Figure 1-3) did not vary significantly between the treatments for the days the assessments were conducted during the cropping cycle. In the Botany Garden (Figure 1) the percentage damaged leaves increased by $10 \%$ over a ten-day period however, the level of infestation observed did not require pesticide application due the economic threshold not being attained. Similar results were observed for callaloo cultivated at Sydney Pagon (Figure 3) and the Botany Garden Plot. The callaloo cultivated at Douglas Castle (Figure 2) had the highest levels of percentage damage leaves of 80 to $100 \%$. After the second application, twenty-five days after transplanting, a decrease in damage was observed with the synthetic pesticide having 
a significant difference $(\mathrm{p}=0.034)$ from the other two applications (control and biorational). However, forty days after transplanting the assessment yielded no significant differences between the three treatments applied.

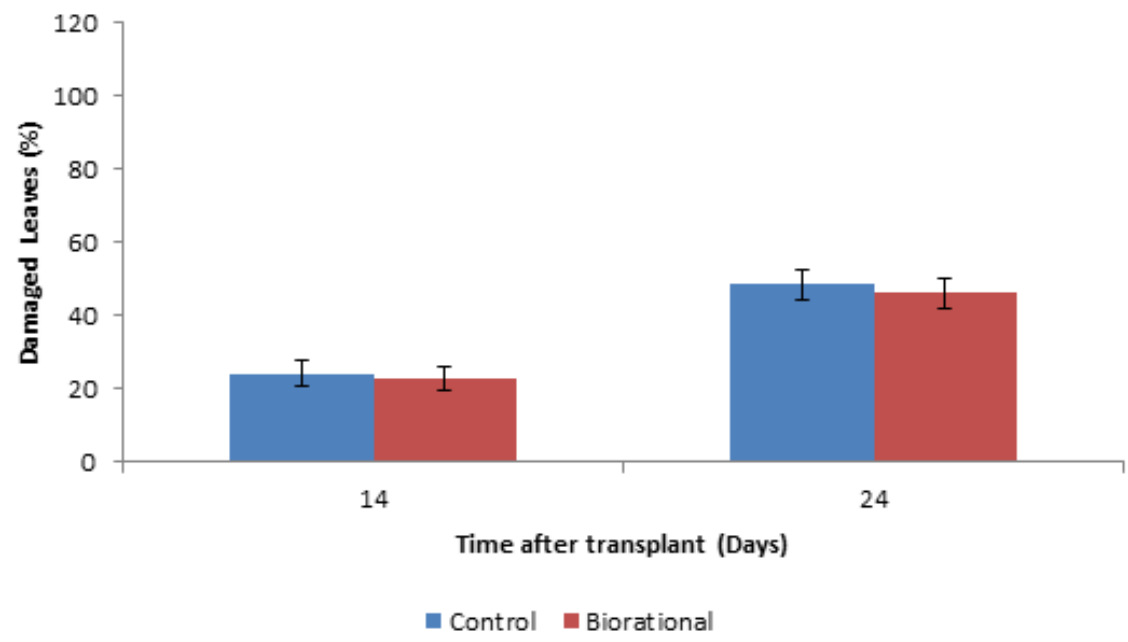

Figure I Percentage of damaged callaloo, Amaranth xanthosoma leaves in experimental plots at the Botany Garden, UWI Mona.

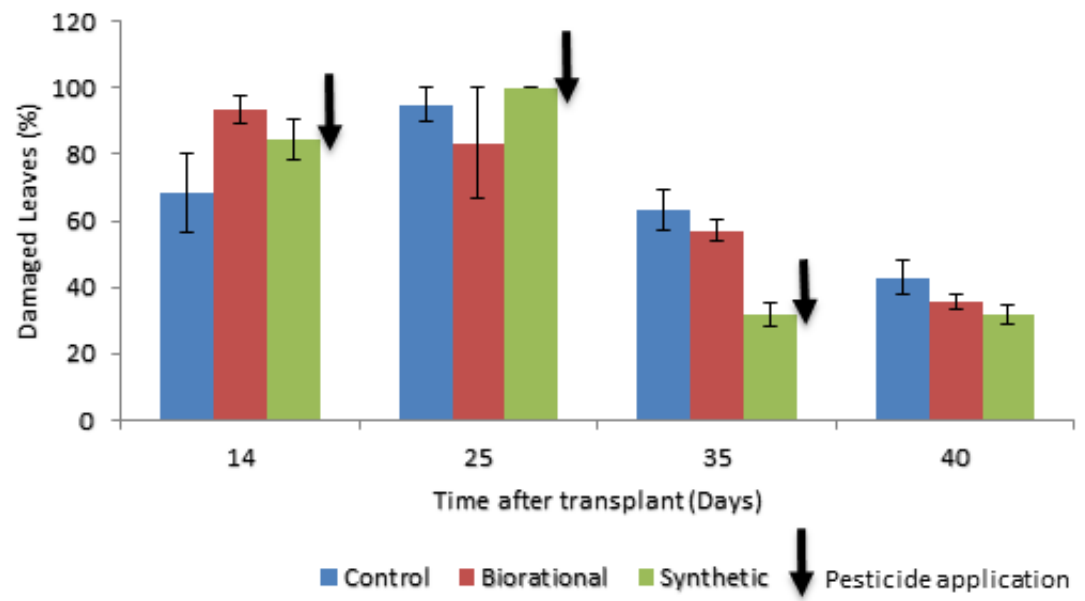

Figure 2 Percentage of damaged callaloo, Amaranth xanthosoma leaves in experimental plot at Douglas Castle, St. Ann.

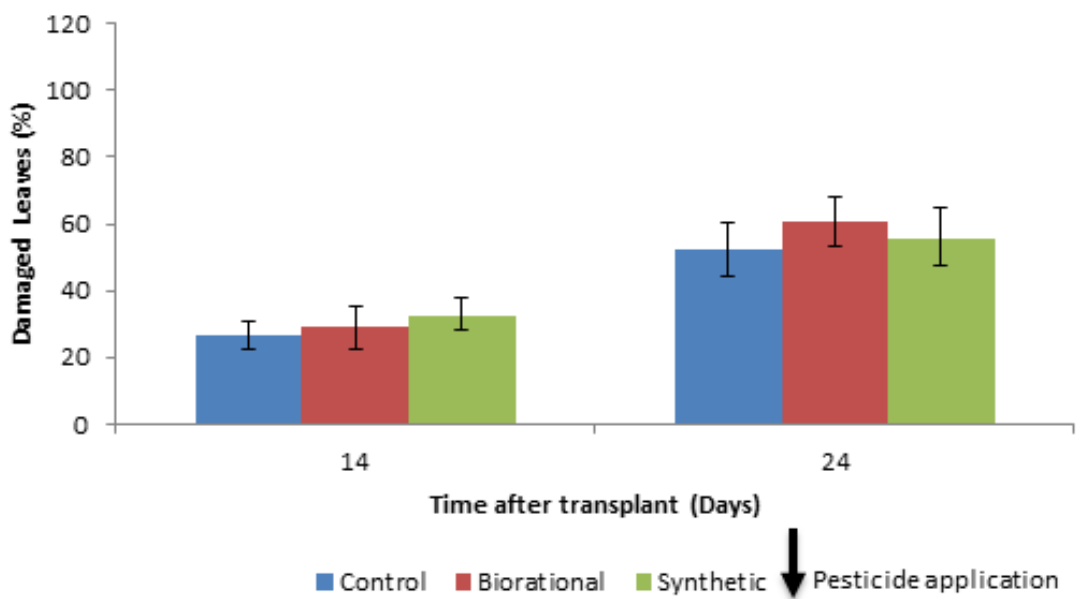

Figure 3 Percentage of damaged callaloo, Amaranth xanthosoma leaves in experimental plots at the Sydney Pagon Academy, St Elizabeth.

The pak choy cultivated on the three plots (Figure 4-6) did not vary significantly with respect to percentage damaged leaves, except for the final assessment at the Douglas Castle plot where a significant difference $(\mathrm{p}=0.012)$ was observed twenty-nine days after planting between the synthetic and the other two treatments (control and biorational). The Botany Garden (Figure 4) and the Sydney Pagon (Figure 6) plots had an increase in the percentage damaged leaves after each insecticide application. While in the Douglas Castle plot 
(Figure 5) once the economic threshold was attained fourteen days after transplanting the percentage damaged leaves decreased and remained fairly constant with the exception of the synthetic treatment that showed an increase of $26 \%$ when compared to a $4 \%$ and $7 \%$ decrease for the biorational and control treatments.

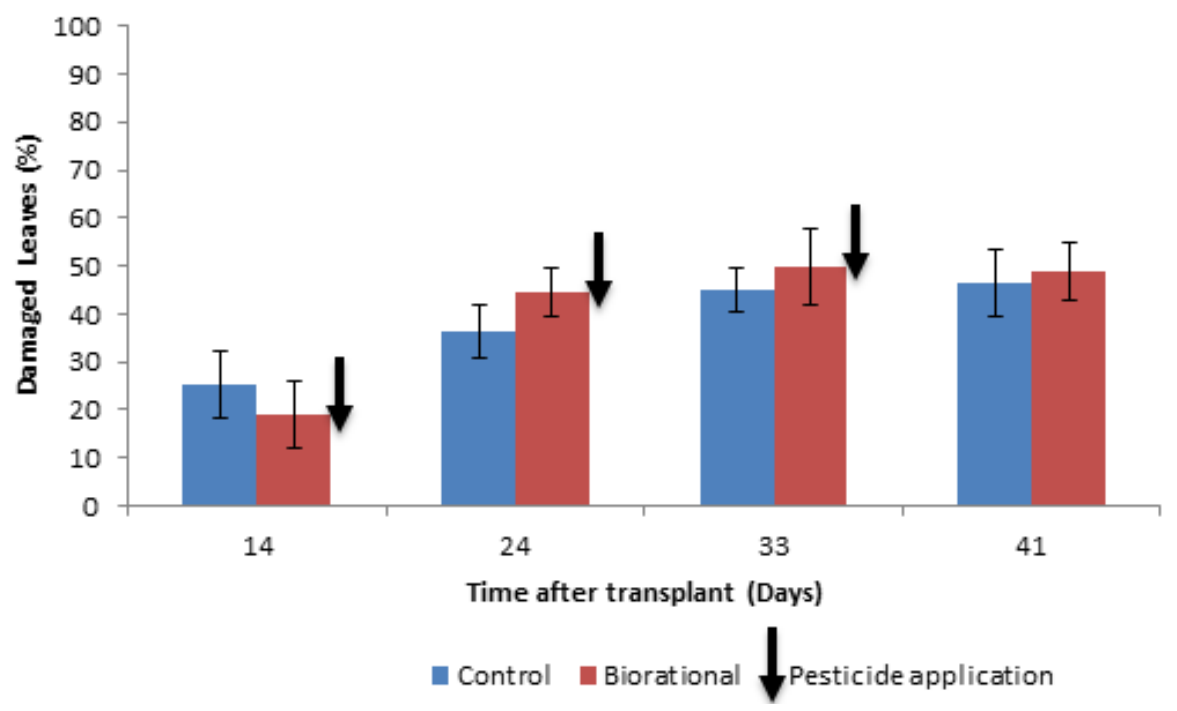

Figure 4 Percentage of damaged Pak Choy, Brassica rapa leaves in experimental plot at the Botany Garden, UWI Mona.

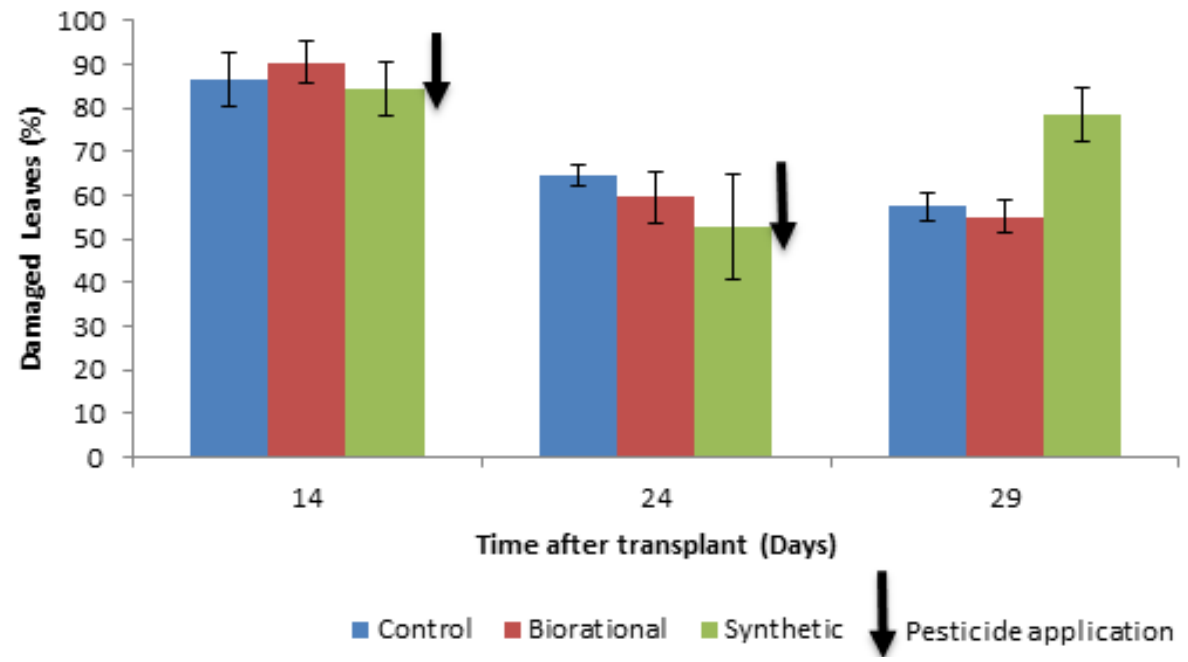

Figure 5 Percentage of damaged Pak Choy, Brassica rapa leaves in experimental plot at Douglas Castle, St. Ann.

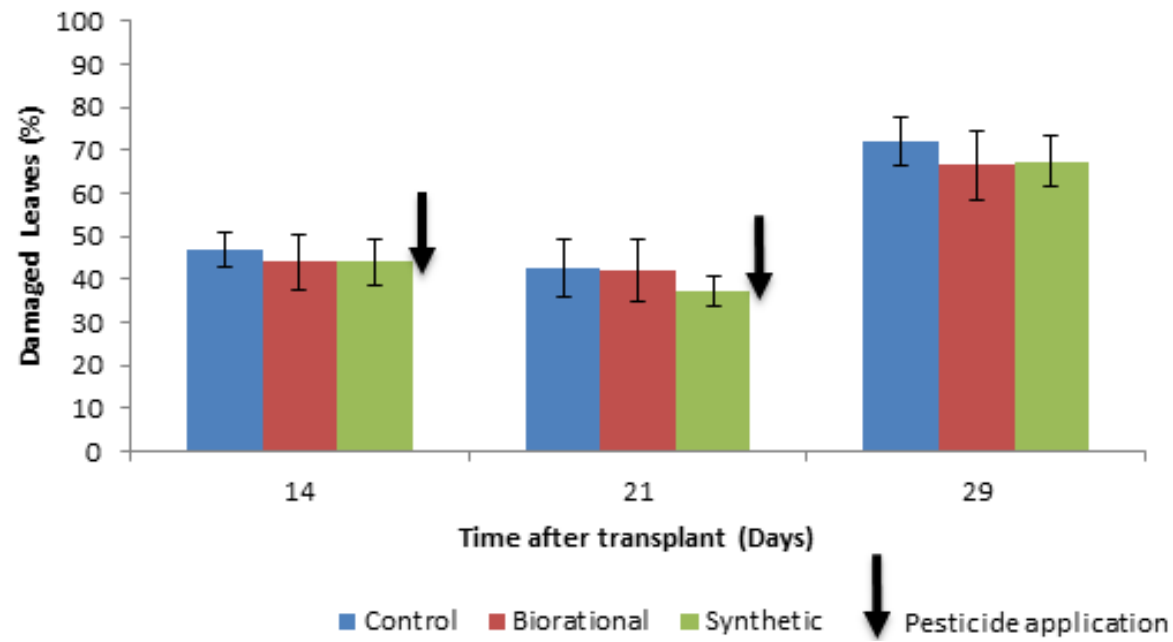

Figure 6 Percentage of damaged Pak Choy, Brassica rapa leaves in experimental plots at Sydney Pagon Academy, St. Elizabeth. 


\section{Leaf area lost}

In (Figure 7) the leaf area lost for callaloo cultivated at the Botany Garden was less than $0.05 \%$ leaf area lost after fourteen days transplanting. After twenty-four days another assessment was conducted that demonstrated an increase of $0.147 \%$ leaf area lost while the biorational treatment slightly increased by $0.046 \%$ leaf area lost with a significant difference $(p<0.05)$ between the two treatments. The Douglas Castle Plot (Figure 8 ) varied significantly ( $\mathrm{p}$ $<0.05$ ) between treatments with the synthetic treatment accounting for $0.401 \%$ and $0.906 \%$, the biorational $0.139 \%$ and $0.695 \%$ and the control having the least of $0.051 \%$ and $0.234 \%$, respectively, for fourteen and twenty-five days after transplanting. A second application was conducted after twenty-five days transplanting were a sharp decrease was observed for all three treatments with an average of $0.122 \%$ leaf area lost. Towards the end of the cropping cycle, forty days after transplanting, the biorational had the least percentage leaf area lost after the synthetic treatment, which was not significantly different from the biorational treatment. However, the biorational treatment was significantly different $(\mathrm{p}<0.05)$ from the control treatment but the synthetic and control treatments were not significantly different. In the Sydney Pagon Plot (Figure 9) the synthetic treatment accounted for the highest percentage leaf area lost followed by the control and biorational treatments with the synthetic treatment being significantly different $(p<0.05)$ from the other two treatments after fourteen days transplanting. A pesticide application was conducted after fourteen days which showed no significant differences observed after the assessment was conducted twenty-four days after transplanting.

The pak choy cultivated at the Botany Garden (Figure 10) did not vary significantly between treatments for the cropping cycle. After two applications were conducted at days fourteen and twenty-four an increase in percentage leaf area lost was observed with the control treatment having a slightly higher percentage leaf area lost compared to the biorational. However, at day forty-one both treatments decreased, but the biorational treated plots had the higher percentage leaf area lost. In Douglas Castle (Figure 11) as assessment was conducted fourteen days after transplanting where no significant difference was observed between treatments. After the treatment was applied at day fourteen all treatments displayed a sharp decrease with the synthetic treatment accounting for the least percentage leaf area lost while being significantly different $(\mathrm{p}<0.05)$ from the biorational and control treatments. In Sydney Pagon (Figure 12) two pesticide applications were conducted after day fourteen and day twenty-one after which the control that accounted for the least percentage leaf area lost, followed by the synthetic and biorational which accounted for the highest percentage leaf area lost. All three treatments were significantly different $(\mathrm{p}<0.05)$ after twenty-nine days of transplanting.

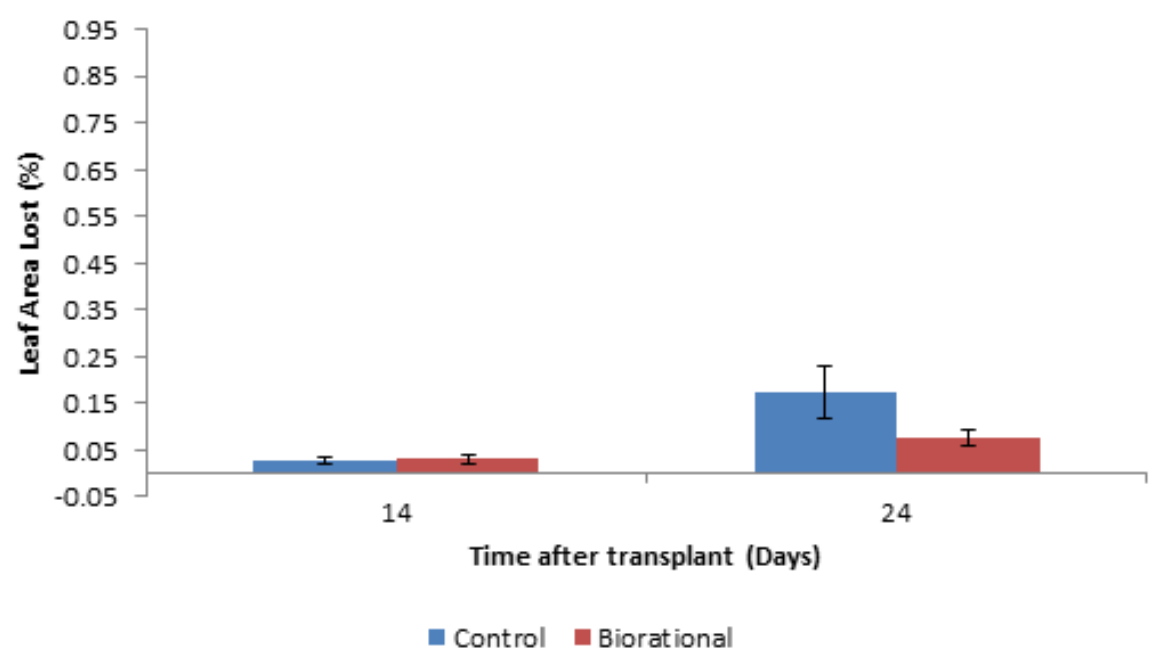

Figure 7 Percentage leaf area lost for callaloo, Amaranth xanthosoma in experimental plot at Botany Garden, UWI Mona.

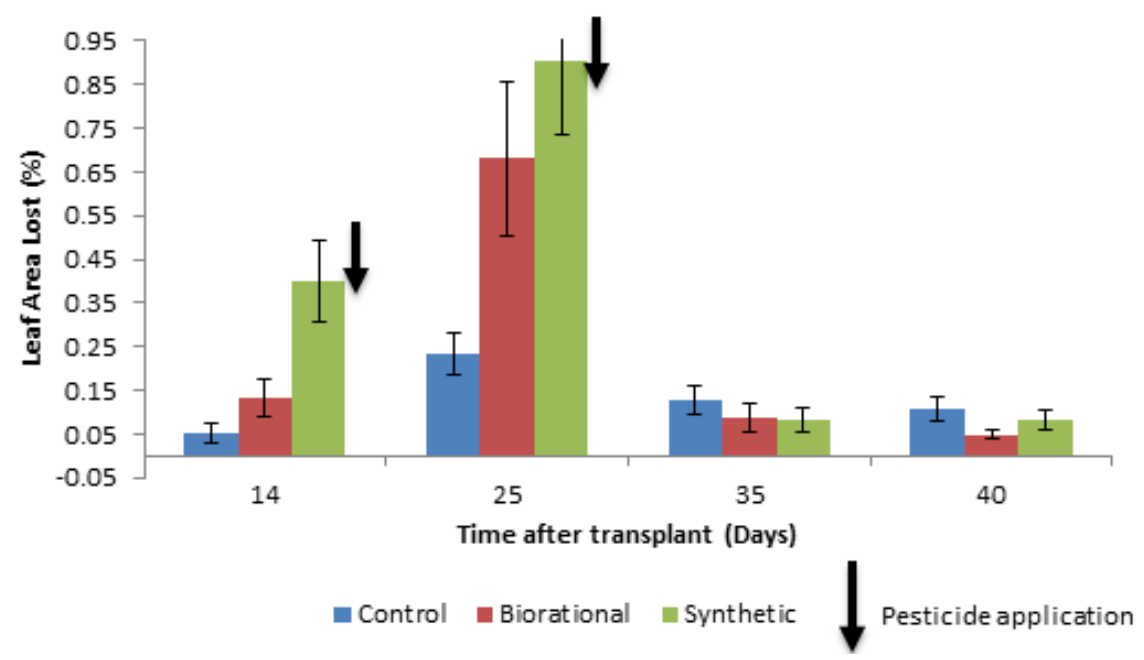

Figure 8 Percentage leaf area lost for callaloo, Amaranth xanthosoma in experimental plot at Douglas Castle, St. Ann.

Citation: Nadia D, Emanuel MA, Robinson DE. The efficacy of alternative (biorational) insecticides in suppressing damage caused by insect pests affecting callaloo, Amaranth xanthosoma and pak choy, Brassica rapa, production in Jamaica. Horticult Int J. 202 I;5(2):5 I-59. DOI: I0.I5406/hij.202I.05.00203 


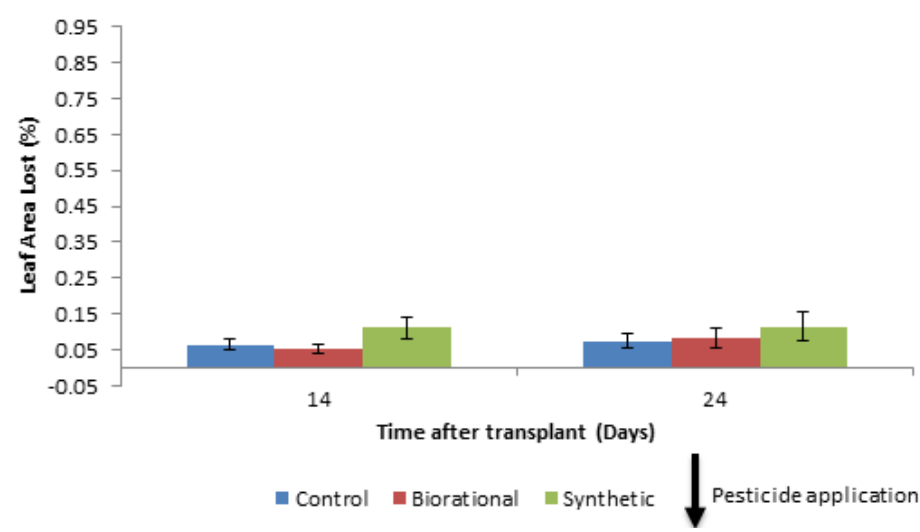

Figure 9 Percentage leaf area lost for callaloo, Amaranth xanthosoma in experimental plot at Sydney Pagon Academy, St Elizabeth.

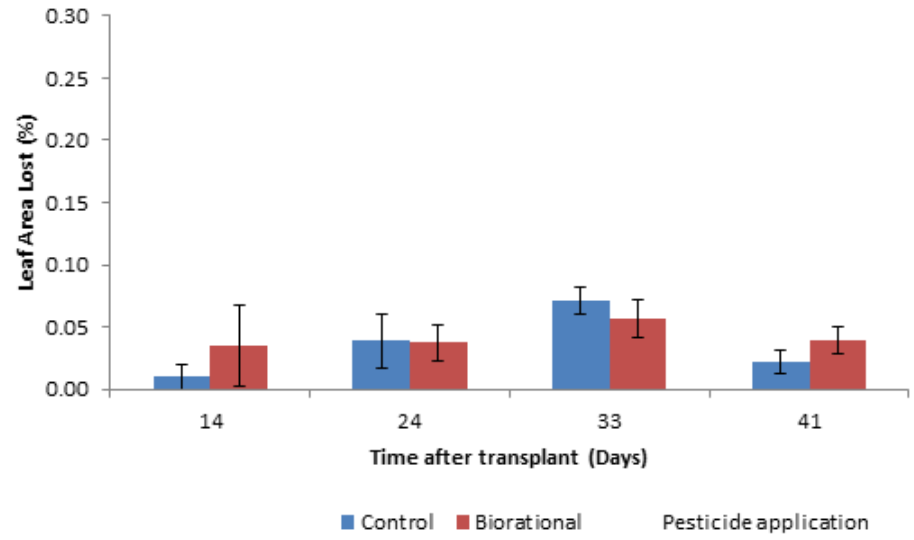

Figure 10 Percentage leaf area lost for Pak Choy, Brassica rapa in experimental plot at the Botany Garden, UWI Mona.

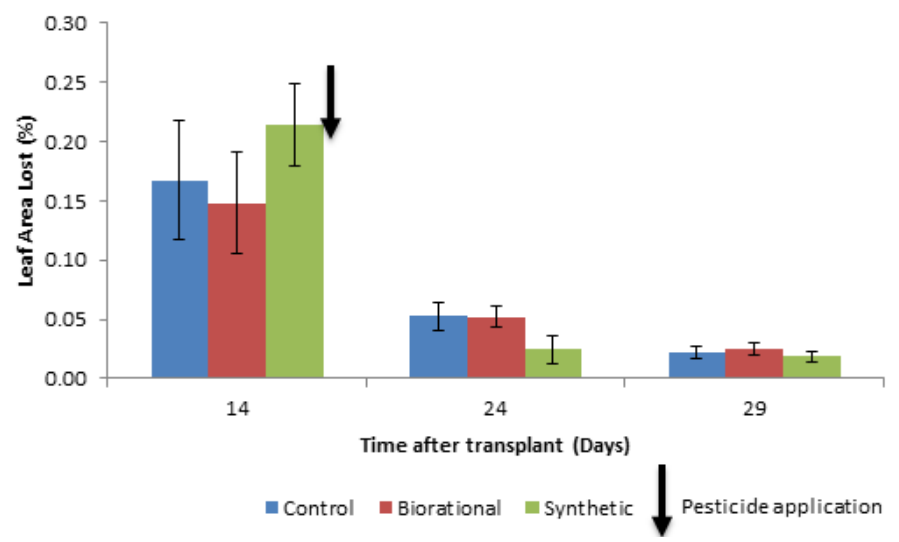

Figure II Percentage leaf area lost for Pak Choy, Brassica rapa in experimental plot at Douglas Castle, St.Ann.

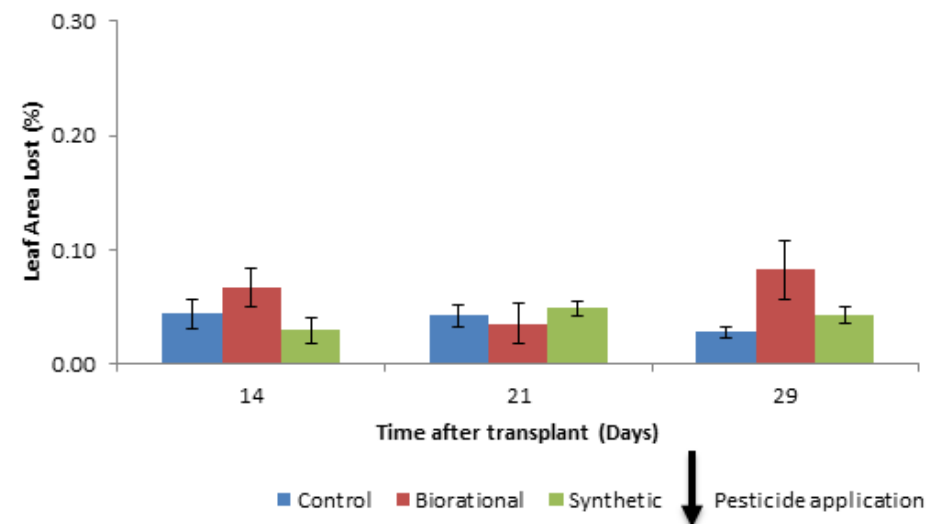

Figure 12 Percentage leaf area lost for Pak Choy, Brassica rapa in experimental plot at the Sydney Pagon Academy, St Elizabeth.

Citation: Nadia D, Emanuel MA, Robinson DE. The efficacy of alternative (biorational) insecticides in suppressing damage caused by insect pests affecting callaloo, Amaranth xanthosoma and pak choy, Brassica rapa, production in Jamaica. Horticult Int J. 202 I;5(2):5 I-59. DOI: I0.15406/hij.202I.05.00203 


\section{Vegetable yield}

For the callaloo crop cultivated in the Botany Garden (Figure 13) a significant difference $(p<0.05)$ was observed between the total and marketable yield for both the control and biorational treatments. In comparison the biorational treatment accounted for the least weight of marketable yield with a difference of $54.2 \mathrm{~g}$ when compared to the control treatment. The damage weight accounted for more than half the weight of the harvested plants in the biorational treated plots. On the other hand, the control plots accounted for less than half the damaged weight. In Douglas Castle (Figure 14) no significant differences were observed in the control between the total weight and marketable yield. The biorational and synthetic treatments accounted

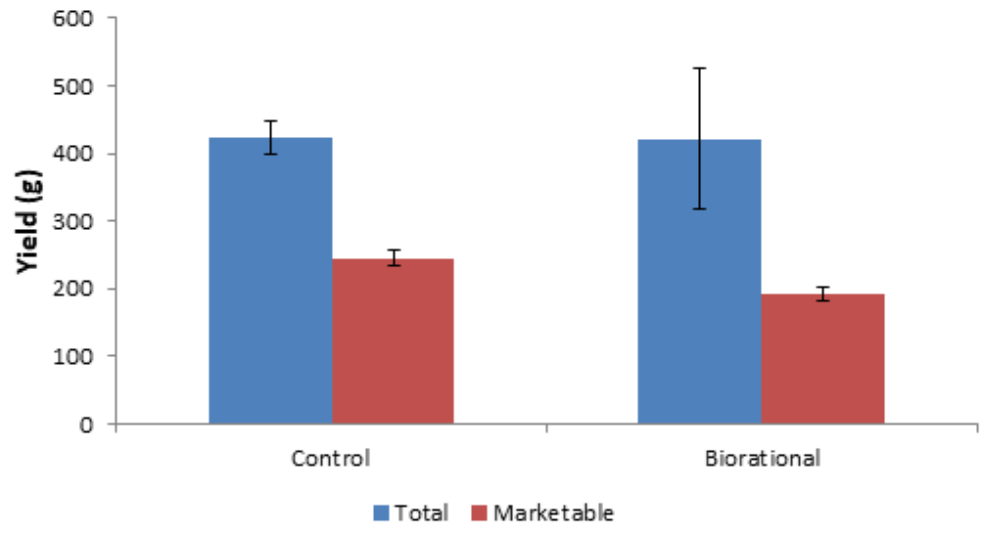

Figure 13 Callaloo, Amaranth xanthosoma harvested in experimental plot at the Botany Garden, UWI Mona.

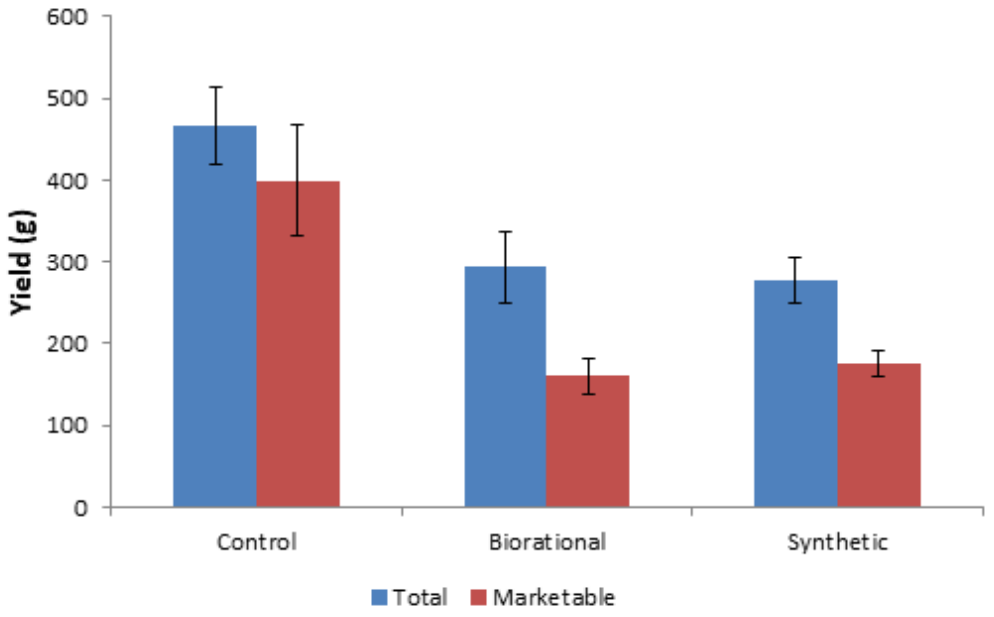

Figure 14 Callaloo, Amaranth xanthosoma harvested in experimental plot at Douglas Castle Plot, St. Ann.

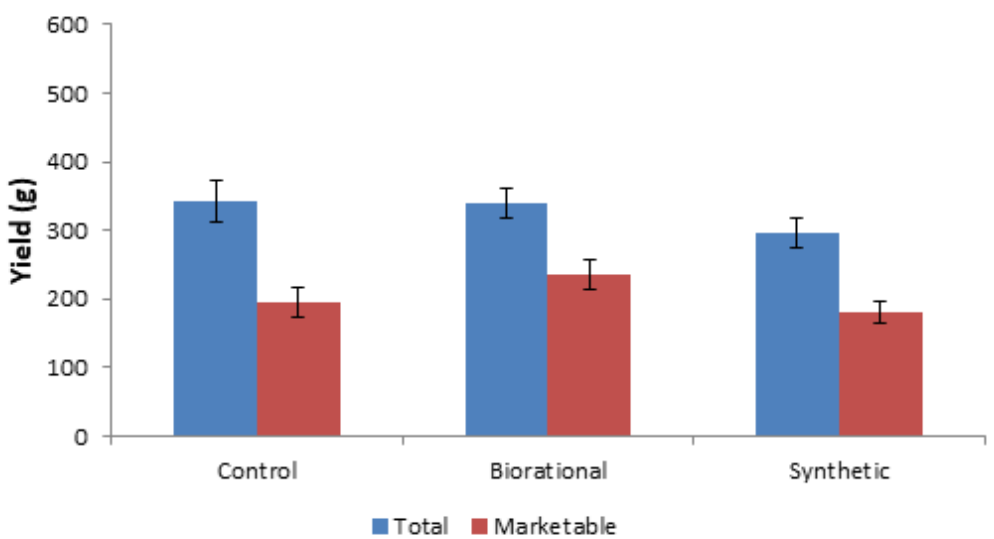

Figure 15 Callaloo, Amaranth xanthosoma harvested in experimental plot at the Sydney Pagon Academy, St Elizabeth. 
In the pak choy cultivated in the Botany Garden (Figure 16) significant differences $(p<0.05)$ were observed between the total and marketable yield for both the control and biorational treatment. The difference in total and marketable yields were $150 \mathrm{~g}$ and $93.6 \mathrm{~g}$, respectively, greater in the biorational treated plots than the control plots. In Douglas Castle (Figure 17) there was a significant difference $(\mathrm{p}<0.05)$ observed in the control and biorational treatments between the total yield and the marketable yield. There was no significant difference observed for the synthetic treatment between the total yield harvested and the marketable yield harvested. The largest margin of difference between the total yield harvested and the marketable yield harvested was observed in the control treatment with a difference of $193.9 \mathrm{~g}$ followed by the biorational treatment with a difference of 171.2g. The synthetic treatment had the lowest total yield but accounted for the second highest marketable yield after the biorational treatment. In Sydney Pagon Academy (Figure 18) significant differences were observed for all three treatments between the total yield harvested and the marketable yield. The control treatment accounted for the least difference of $146.8 \mathrm{~g}$, followed by the synthetic treatment with a difference of $115.1 \mathrm{~g}$. The biorational treatment had the least difference of $102.8 \mathrm{~g}$ but accounted for the highest marketable yield.

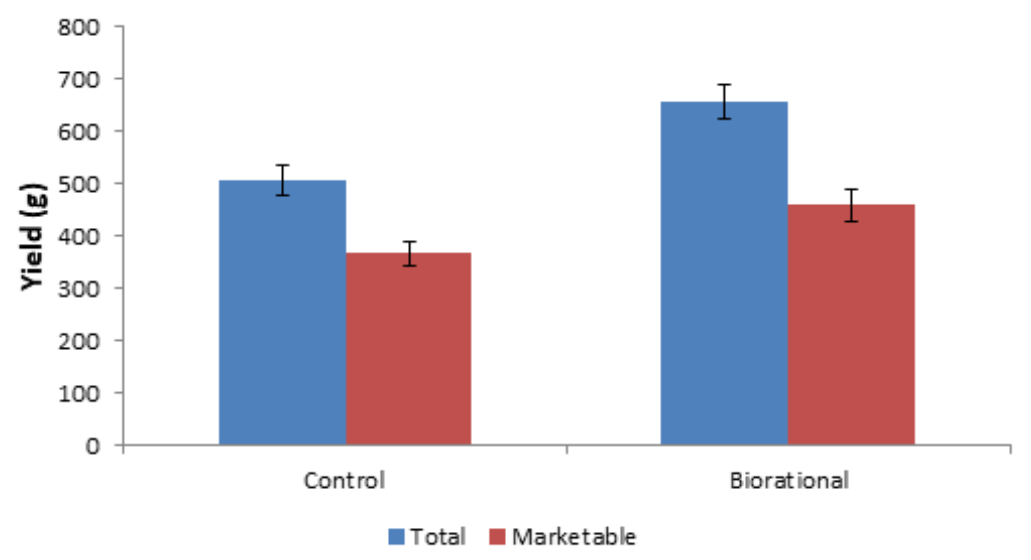

Figure 16 Pak Choy, Brassica rapa harvested in experimental plot at the Botany Garden, UWI Mona.

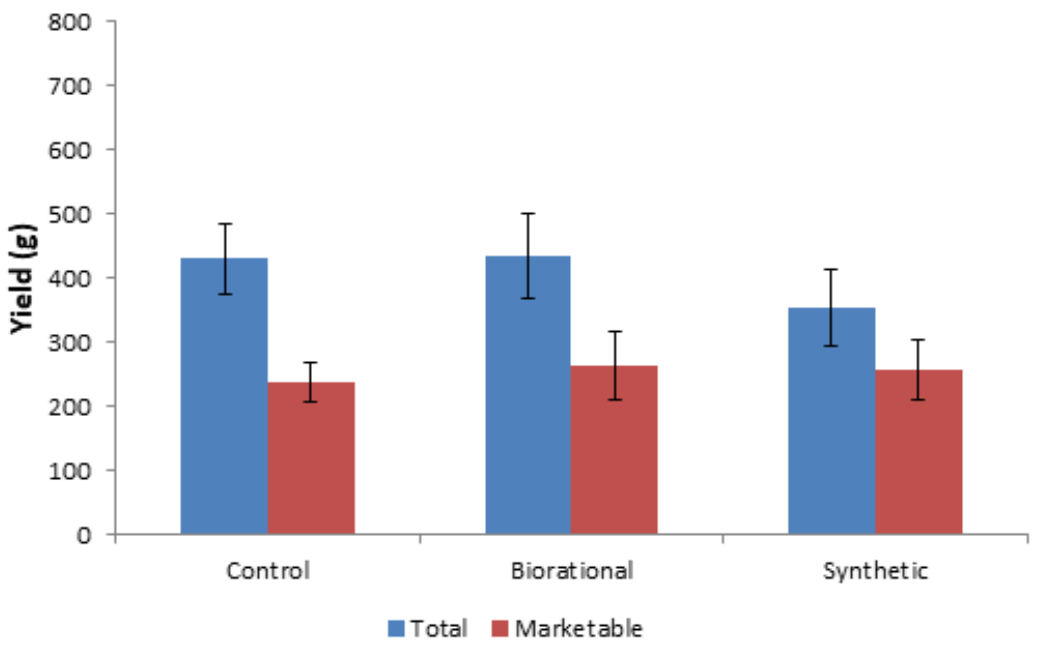

Figure 17 Pak Choy, Brassica rapa harvested in experimental plot at Douglas Castle, St. Ann.

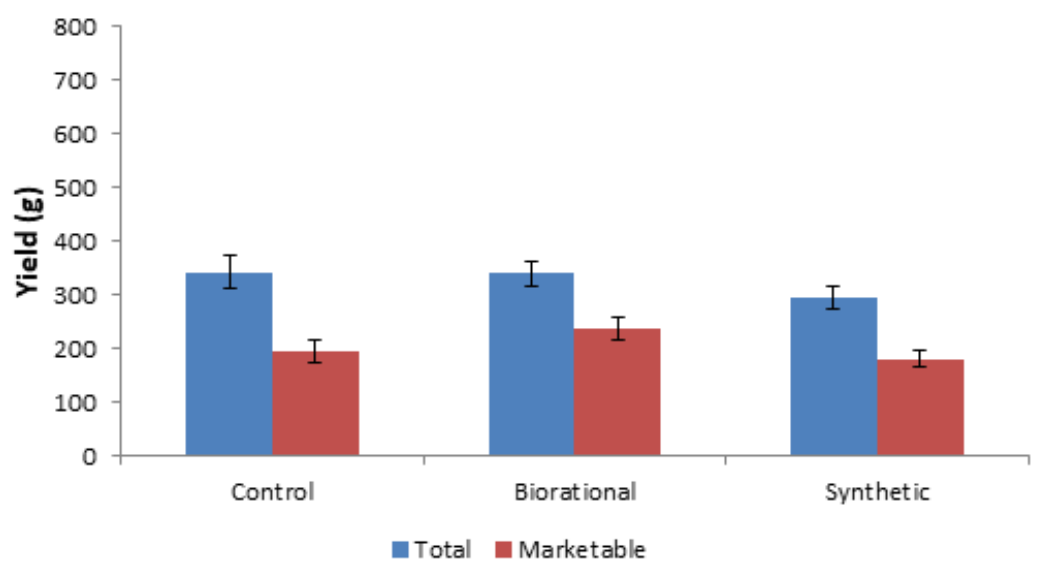

Figure 18 Pak Choy, Brassica rapa harvested in experimental plot at Sydney Pagon Academy, St Elizabeth. 


\section{Discussion}

This is not surprising as pest numbers and activity would be impacted by the ecological conditions and agronomic practices at each site. It was interesting to note that while the number of damaged leaves for the crops reached a high of between 70 and $100 \%$ the total leaf area lost never exceeded $1 \%$. Theoretically, this would be below any economic threshold based simply on mass lost, however, the products are sold fresh to the final consumer who generally considers aesthetics as an indication of quality. This results in the need for the farmer to lower the economic threshold, thus increase the use of pesticides to effectively minimise the pest damage. A nationwide vegetable farmer consultation would assist the farmer in understanding the effective use of pesticide applications and attainment of economic thresholds in maintaining low pest populations by reducing the frequency of pesticide applications.

There was no significant difference in the leaf area lost in the treated callaloo and pak choy plots may suggests the impact of the biorationals on the pest activity is not significantly different from its synthetic counterpart. Among the various biopesticides neem Azadirachta indica has proven to be a highly reliable source for effective pest management, it tops the list of 2400 botanicals used as biopesticide worldwide. ${ }^{3}$ The bacterial spores from Bacillus thuringiensis $(\mathrm{Bt})$ is the most important entomopathogenic microorganism used in crop protection and has displayed toxicity against an increasing number of insect pest from the orders Lepidoptera, Coleoptera, Hymenoptera and Hemiptera. ${ }^{4}$ A cost-benefit analysis would be helpful in the decision making process as there is a possibility that these biorationals may have a positive cost-benefit ratio ${ }^{5}$ despite the higher cost for the purchasing of biorationals. Over the past decades the increasing development of synthetic insecticides and persuasive usage is driven by their lower, effectiveness and longer lasting properties. ${ }^{6}$ However, after the economic thresholds were determined and the various insecticides applied a reduction was observed throughout the plots, both the biorationals and the synthetic pesticides were effective in reducing the area lost via pest damage. Based on the action of the pest in question and stage in the pest life cycle the farmer would determine the mode action of the biorational applied (contact or antifeedant) in achieving a more sustained reduction. The use of biorationals for vegetable production in Jamaica should be driven by policy intervention for the drastic reduction in the risks associated with human health and the environment destruction of the natural enemies that possess positive interactions in maintaining the pest populations below economic thresholds. It is therefore necessary to assess the possible effects of pesticide application on these naturally occurring control factors as negative effects of pesticides on natural enemies associated with agroecosystems has been of concern worldwide. ${ }^{7}$

In most cases the marketable yield was significantly different ( $\mathrm{p}<$ 0.001 ) from the harvested yield and reiterate the earlier point about the impact of market demand and requirements on economic thresholds and pest management for crops sold as fresh produce. Even some level of minimal processing may be able to reduce that loss. In most cases there were no significant differences in the marketable yield obtained from plots treated with the synthetic pesticides and those treated with the biorationals. This clearly indicates the potential of these biopesticides as suitable alternatives to the synthetic pesticides. The fact that the yield from the control at some sites was similar to or better than that obtained from treated plots, despite the fact that pest damage was higher during the growing phase of the crop, may suggest a negative impact of the pesticides on soil microorganisms ${ }^{8}$ which might have impacted the total yield.

\section{Conclusion}

While the data generated in this phase of the research needs to be verified, there are some clear trends that indicate the potential for biopesticides to be a cost-effective alternative to highly hazardous pesticides. However, there may be the need to adjust farming practices to include a more integrated approach to pest and nutrient management to improve the cost-benefit ratio of using biorationals and similar alternatives.

The use of biorationals has proven to be effective in crop protection, in order to significantly reduce the high residual levels of synthetic pesticides entering the food chain. The regulatory framework should therefore reflect more tolerant polices that will make provision for easier access to the development, marketing and purchasing of biorationals as opposed to tougher measures imposed on their synthetic counterparts. More research is warranted in the development of more effective biorationals that may target more than one species of pest at the same time while reducing the rate of application on the crop.

Educating the younger generation of agricultural enthusiast of the negative implications of synthetic pesticide usage and the positive implications of biopesticides on human health and the environment will make provision for a new generation of farmers who will encompass moral and ethical values into their approach towards crop production and protection. As the older generation of farmers are difficult to pursuade to make the transition from synthetic applications to the biorationals.

\section{Acknowledgments}

Research work supported by the Food and Agriculture Organization of the United Nations ("FAO") in support of services towards the project entitled "Disposal of Obsolete Pesticides including POPs Promotion of Alternatives and Strengthening Pesticides Management in the Caribbean."

\section{Conflicts of interest}

Authors declare no conflict to of interest exists.

\section{References}

1. Horowitz AR, Ellsworth PC. Ishaaya I. Biorational control of arthropod pests: Application and resistance management. 2009;1-21.

2. Carvalho FP. Pesticides, environment and food safety. 2017;6(2):48-60.

3. Adhikari K, Bhandari S, Niraula D, et al. Use of neem (Azadirachta indica A. Juss) as a biopesticide in agriculture: A review. Journal of Agriculture and Applied Biology. 2020;1(2):100-117.

4. Dominguez-Arrizabalaga M., Villanueva M, Escriche B, et al. Insecticidal Activity of Bacillus thuringiensis proteins against coleopteran pests. Toxins (Basel). 2020;29:12(7):430.

5. Amoabeng BW, GM Gurr, CW Gitau, et al. Cost:benefit analysis of botanical insecticide use in cabbage: Implications for small holder farmers in developing countries. Crop Protection. 2014;57:71-76.

6. Casida JE, GB. Ouistad. Annaual review of entomology. 1998;43:1-16

7. Stark JD, JE Banks, S Acheampong. Estimating susceptibility of biological control agents to pesticides: influence of life history strategies and population structure Biological Control. 20004;29:392-398.

8. Aktar WD, Sengupta, A Chowdhury. Impact of pesticides use in agriculture: Their benefits and hazards. Interdisciplinary Toxicology. 2009;2(1):1-12. 